\title{
Molecular docking, synthesis and in vitro antimalarial evaluation of certain novel curcumin analogues
}

\author{
Chandrajit Dohutia $^{1^{*}}$, Dipak Chetia ${ }^{2}$, Kabita Gogoi ${ }^{3}$, Dibya Ranjan Bhattacharyya ${ }^{3}$, \\ Kishore Sarma ${ }^{3}$ \\ ${ }^{1}$ Department of Pharmaceutical Sciences, Assam Down Town University, Guwahati, Assam, India, \\ ${ }^{2}$ Dibrugarh University, Dibrugarh, Assam, India, ${ }^{3}$ Regional Medical Research Centre NE (Indian Council of Medical \\ Research), Dibrugarh, Assam, India
}

\begin{abstract}
The receptor protein PfATP6 has been identified as the common target of artemisinin and curcumin. The work was initiated to assess the antimalarial activity of six curcumin derivatives based on their binding affinities and correlating the in silico docking outcome with in vitro antimalarial screening results. A ligand library of thirty two Knoevenagel condensates of curcumin were designed and docked against PfATP6 protein and six compounds with the best binding scores were synthesized and screened for their antimalarial activity against the sensitive 3D7 strain of Plasmodium falciparum. ADME/Tox, pharmacokinetic and pharmacodynamic profiles of the designed compounds were analyzed and reported. 4-FB was found to have similar binding energy to the standard artemisinin ( -6.75 and -6.73 respectively) while 4-MB, 3-HB, 2-HB, B, 4-NB displayed better binding energy than curcumin $(-5.95,-5.89,-5.68$, $-5.35,-5.29$ and -5.25 respectively). At a dose of $50 \mu \mathrm{g} / \mathrm{mL}$ all the six compounds showed $100 \%$ schizont inhibition while at $5 \mu \mathrm{g} / \mathrm{ml}$, five showed more than $75 \%$ inhibition and better results than curcumin. $4-\mathrm{FB}$ showed the best activity with $97.8 \%$ schizonticidal activity. The in vitro results superimpose the results obtained from the in silico study thereby encouraging development of promising curcumin leads in the battle against malaria.
\end{abstract}

Keywords: Curcumin/synthesis. Curcumin/antimalarial activity. Curcumin/Knoevenagel condensates. PfATP6. Malaria. Docking. In vitro. ADME/Tox.

\section{INTRODUCTION}

Globally malaria is beginning to show signs of abatement, yet it still ravages millions across the globe. Its worldwide figures border on two hundred million clinical cases and half a million deaths (World Malaria Report, 2014). Several people in India succumbed to this dreaded disease in the past couple of years. Counteraction to most of the standard antimalarials is increasing at a startling rate resulting in substituting combinations of sulfadoxine and pyrimethamine with artesunate-mefloquine in many states of India (NVBDCP, 2014). Information regarding the development of resistance to the most effective drugs like artemisinin, mefloquine and piperaquine in Greater

\footnotetext{
*Correspondence: C. Dohutia. Department of Pharmaceutical Sciences, Dibrugarh University Nayanpur, Guwahati-781005, Assam, India. E-mail: chnadrajit@gmail.com.
}

Mekong areas and south East Asian countries of Thailand and Cambodia has also come to light (World Health Organization, 2014). Resistance to artemisinins has also been recently detected in the border areas of India and Myanmar (Tun et al., 2015). Thereby, newer, more potent and less toxic antimalarial leads, which can effectively cripple malaria are the need of the hour. Despite the urgent requirement of a new and potent antimalarial agent, drug discovery for malaria is an uphill task (Olliaro, 2001; Gelb, 2007). The continuous evolution of the drug discovery methods and high quality lead generation process is likely to deliver potential compounds with better therapeutic activity (Ratti, Trist, 2001). Turmeric has been widely reported as a principle component of traditional remedies for treating malaria and fever in India, Nigeria and Samoa (Odugbemi et al., 2007; Uhe, 1974; Shankar, Venugopal, 1999). Curcumin 1,7-bis-(4-hydroxy-3-methoxyphenyl)1,6-heptadiene-3,5-dione (diferuloyl methane), a major 
hydrophobic polyphenol is derived from the rhizome (turmeric) of the herb Curcuma longa. Chemically, it is a bis- $\alpha, \beta$-unsaturated $\beta$-diketone that exhibits ketoenol tautomerism. It has, of late generated considerable amount of interest due to a plethora of therapeutical properties which includes antioxidant, anti-inflammatory, antimicrobial, and anticarcinogenic activities. It exhibits hepatoprotective and nephroprotective activities, suppresses thrombosis, protects against myocardial infarction, and has hypoglycemic and antirheumatic properties (Aggarwal, Harikumar, 2009; Kunnumakkara, Anand, Aggarwal, 2008; Ahsan et al., 1999; Dubey et al., 2008; Liang et al., 2008). Moreover, it has been shown to be extremely safe at high doses in various animal and human models (Hatcher et al., 2008). Cheng et al. (2001) reported administration of curcumin up to $8 \mathrm{~g}$ /day to $12 \mathrm{~g} /$ day for a period of 3 months without any toxic effects (Cheng et al., 2001) Curcumin along with artemisinin has been noted to prevent revival of malaria parasites and death in in vivo studies (Reddy et al., 2005; Nandakumar et al., 2006). In combination with Andrographis paniculata and Hedyotis corymbosa extracts, it has shown a synergistic effect in vitro and also in in vivo rodent malaria models (Mishra et al., 2009). Recent studies have brought to light the efficacy of curcumin against Plasmodium falciparum cultures and Plasmodium berghei-infected mice (Manohar et al., 2013). Derivatives and analogues of curcumin have been proclaimed to have improved efficacy against $P$. falciparum cultures than the parent molecule (Mishra et al., 2008). Replacement or removal of the phenolic group leads to a loss of activity which suggests that two unsubstituted phenolic groups are necessary for curcumin's antimalarial activity (Eckstein et al., 2003). P. falciparum $\mathrm{Ca}(2+)$-ATPase (PfATP6) the parasite orthologue of mammalian Sarcoplasmic-Endoplasmic Reticulum Ca2 ${ }^{+}$-ATPase (SERCA), has been confirmed to be the molecular target of artemisinins, the most potent of all antimalarials. Through docking simulation studies, it was found that curcumin effectively inhibited PfATP6 through hydrophobic interactions and hydrogen bonds, leading to its antimalarial action (Knoevenagel, 1898). Though studies targeting the PfATP6 protein with curcumin and artemisinin have been individually proclaimed (Hong-Fang, Liang, 2009), in silico studies on a series of curcumin derivatives, their consequent synthesis based on binding energies and their correlation with in vitro antimalarial studies as not been reported earlier. Knoevenagel condensates are products obtained by the Knoevenagel condensation reaction, which is a nucleophilic addition of an active hydrogen compound to a carbonyl group followed by a dehydration reaction in which a molecule of water is eliminated. The study involved designing and synthesizing Knoevenagel condensates of curcumin as per their binding affinities to the PfATP6 protein, interpretation of the ADME/Tox, pharmacokinetic, pharmacodynamic data and in vitro antimalarial assessment in the hope of obtaining new drug candidates with potent schizonticidal activity.

\section{MATERIAL AND METHODS}

\section{Target identification}

The protein PfATP6, also known as PfSERCA is a $139 \mathrm{kDa}$ protein composed of 1228 amino acids which share $51 \%$ identity with mammalian SERCA protein and has been proved to be a major molecular drug target of artemisinin antimalarials (Eckstein et al., 2003). HongFang Ji and Liang Shen used PfATP6 as drug target for curcumin binding which indicated its interactions with PfATP6 through hydrophobic and hydrogen bonds and its subsequent inhibition (Hong-Fang, Liang, 2009). As a result, in the present study derivatives of curcumin were designed and targeted against PfATP6 to unveil their antimalarial potential. In absence of crystallographic structure of PfATP6, the modeled structure of PfATP6, (PDB ID: 1U5N) designed by Krishna and Salas-Burgos based on open conformation template 1SU4 was used (Krishna et al., 2009; Salas-Burgos et al., 2004)

\section{Ligand dataset preparation and optimization}

A ligand library of 32 curcumin derivatives was designed using ChemOffice 2010 (designing software). Selection of the ligands was based on structural similarity to the parent compound curcumin. The parent curcumin structural skeleton was retained, and modification was made via the addition of an aryl aldehyde to the active hydrogens at position 4 of the curcumin nucleus (Figure 1) in the hope of increasing its antimalarial efficacy. Table I shows the positions of different substituents on the parent curcumin molecule. The positions of the different substituents are indicated in Figure 2. The "Prepare ligand" protocol of DS3.5 was used to prepare the ligands which removes duplicate structures, standardizes the charges

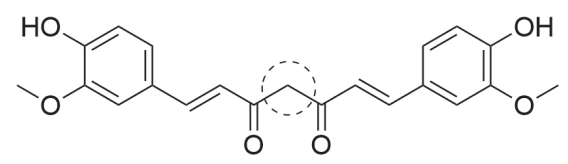

(1E,6E)-1,7-bis(4-hydroxy-3-methoxyphenyl)hepta-1,6-diene-3,5-dione

FIGURE 1 - Curcumin and the position of its modification. 
TABLE I - Data set of compounds used for docking study

\begin{tabular}{|c|c|c|c|c|c|c|}
\hline SI No. & Ligand & $\mathbf{R}_{1}$ & $\mathbf{R}_{2}$ & $\mathbf{R}_{3}$ & $\mathbf{R}_{4}$ & $\mathbf{R}_{5}$ \\
\hline$\overline{1 .}$ & $\mathrm{B}$ & $\mathrm{H}$ & $\mathrm{H}$ & $\mathrm{H}$ & $\mathrm{H}$ & $\mathrm{H}$ \\
\hline 2. & 2-HB & $\mathrm{OH}$ & $\mathrm{H}$ & $\mathrm{H}$ & $\mathrm{H}$ & $\mathrm{H}$ \\
\hline 3. & $3-\mathrm{HB}$ & $\mathrm{H}$ & $\mathrm{OH}$ & $\mathrm{H}$ & $\mathrm{H}$ & $\mathrm{H}$ \\
\hline 4. & 2,4-DHB & $\mathrm{OH}$ & $\mathrm{H}$ & $\mathrm{OH}$ & $\mathrm{H}$ & $\mathrm{H}$ \\
\hline 5. & 3,4,5-ТНB & $\mathrm{H}$ & $\mathrm{OH}$ & $\mathrm{OH}$ & $\mathrm{OH}$ & $\mathrm{H}$ \\
\hline 6. & 3-MEOB & $\mathrm{H}$ & $\mathrm{OCH}_{3}$ & $\mathrm{H}$ & $\mathrm{H}$ & $\mathrm{H}$ \\
\hline 7. & 4-MEOB & $\mathrm{H}$ & $\mathrm{H}$ & $\mathrm{OCH}_{3}$ & $\mathrm{H}$ & $\mathrm{H}$ \\
\hline 8. & 2,5-DMEOB & $\mathrm{OCH}_{3}$ & $\mathrm{H}$ & $\mathrm{H}$ & $\mathrm{OCH}_{3}$ & $\mathrm{H}$ \\
\hline 9. & 4-H,3-MEOB & $\mathrm{H}$ & $\mathrm{OCH}_{3}$ & $\mathrm{OH}$ & $\mathrm{H}$ & $\mathrm{H}$ \\
\hline 10. & 4-FB & $\mathrm{H}$ & $\mathrm{H}$ & $\mathrm{F}$ & $\mathrm{H}$ & $\mathrm{H}$ \\
\hline 11. & $3,4-\mathrm{DFB}$ & $\mathrm{H}$ & $\mathrm{F}$ & $\mathrm{F}$ & $\mathrm{H}$ & $\mathrm{H}$ \\
\hline 12. & 4-MB & $\mathrm{H}$ & $\mathrm{H}$ & $\mathrm{CH}_{3}$ & $\mathrm{H}$ & $\mathrm{H}$ \\
\hline 13. & 3,4-DMB & $\mathrm{H}$ & $\mathrm{CH}_{3}$ & $\mathrm{CH}_{3}$ & $\mathrm{H}$ & $\mathrm{H}$ \\
\hline 14. & 2,4-DMB & $\mathrm{CH}_{3}$ & $\mathrm{H}$ & $\mathrm{CH}_{3}$ & $\mathrm{H}$ & $\mathrm{H}$ \\
\hline 15. & 4-CLB & $\mathrm{H}$ & $\mathrm{H}$ & $\mathrm{Cl}$ & $\mathrm{H}$ & $\mathrm{H}$ \\
\hline 16. & 2,3-DCLB & $\mathrm{Cl}$ & $\mathrm{Cl}$ & $\mathrm{H}$ & $\mathrm{H}$ & $\mathrm{H}$ \\
\hline 17. & $4-N B$ & $\mathrm{H}$ & $\mathrm{H}$ & $\mathrm{NO}_{2}$ & $\mathrm{H}$ & $\mathrm{H}$ \\
\hline 18. & 4-DMAB & $\mathrm{H}$ & $\mathrm{H}$ & $\mathrm{N}\left(\mathrm{CH}_{3}\right)_{2}$ & $\mathrm{H}$ & $\mathrm{H}$ \\
\hline 19. & $3-\mathrm{NB}$ & $\mathrm{H}$ & $\mathrm{NO}_{2}$ & $\mathrm{H}$ & $\mathrm{H}$ & $\mathrm{H}$ \\
\hline 20. & 4-ISOPB & $\mathrm{H}$ & $\mathrm{H}$ & $\left(\mathrm{CH}_{3}\right)_{2} \mathrm{CH}$ & $\mathrm{H}$ & $\mathrm{H}$ \\
\hline 21. & 4-H,3,5-DMB & $\mathrm{H}$ & $\mathrm{CH}_{3}$ & $\mathrm{OH}$ & $\mathrm{CH}_{3}$ & $\mathrm{H}$ \\
\hline 22. & 2,4,5-TMB & $\mathrm{CH}_{3}$ & $\mathrm{H}$ & $\mathrm{CH}_{3}$ & $\mathrm{CH}_{3}$ & $\mathrm{H}$ \\
\hline 23. & 4-EOB & $\mathrm{H}$ & $\mathrm{H}$ & $\mathrm{OC}_{2} \mathrm{H}_{5}$ & $\mathrm{H}$ & $\mathrm{H}$ \\
\hline 24. & 2,4,6-TMB & $\mathrm{CH}_{3}$ & $\mathrm{H}$ & $\mathrm{CH}_{3}$ & $\mathrm{H}$ & $\mathrm{CH}_{3}$ \\
\hline 25. & 4-EB & $\mathrm{H}$ & $\mathrm{H}$ & $\mathrm{C}_{2} \mathrm{H}_{5}$ & $\mathrm{H}$ & $\mathrm{H}$ \\
\hline 26. & 3-F,4-MB & $\mathrm{H}$ & F & $\mathrm{CH}_{3}$ & $\mathrm{H}$ & $\mathrm{H}$ \\
\hline 27. & 3-F,2-MB & $\mathrm{CH}_{3}$ & $\mathrm{~F}$ & $\mathrm{H}$ & $\mathrm{H}$ & $\mathrm{H}$ \\
\hline 28. & $4-\mathrm{CNB}$ & $\mathrm{H}$ & $\mathrm{H}$ & $\mathrm{CN}$ & $\mathrm{H}$ & $\mathrm{H}$ \\
\hline 29. & $4-\mathrm{AB}$ & $\mathrm{H}$ & $\mathrm{H}$ & $\mathrm{NH}_{2}$ & $\mathrm{H}$ & $\mathrm{H}$ \\
\hline 30. & 2,4-DNB & $\mathrm{NO}_{2}$ & $\mathrm{H}$ & $\mathrm{NO}_{2}$ & $\mathrm{H}$ & $\mathrm{H}$ \\
\hline 31. & 4-MTB & $\mathrm{H}$ & $\mathrm{H}$ & $\mathrm{SCH}_{3}$ & $\mathrm{H}$ & $\mathrm{H}$ \\
\hline 32. & 4-HB & $\mathrm{H}$ & $\mathrm{H}$ & $\mathrm{OH}$ & $\mathrm{H}$ & $\mathrm{H}$ \\
\hline
\end{tabular}<smiles>[R]c1c([R])c([R])c(C=C(C(=O)/C=C/c2ccc(O)c(OC)c2)C(=O)/C=C/c2ccc(O)c(OC)c2)c([R])c1[R]</smiles>

FIGURE 2 - Position of substituents on the benzaldehyde group attached to curcumin via Knoevenagel condensation.

of common groups, calculates the ions and ionization of the ligand's functional groups, generates isomers and tautomers, 2D-3D conversion, verifying and optimizing the structures, and other tasks established by user-defined parameters. Energy minimizations of all the ligands were done by applying CHARMM force field.

\section{Docking of receptor with ligand}

PfATP6 was used as receptor molecule for the docking study to probe the binding free energy between the ligand library and receptor using AutoDock 4.2 (Morris et al., 2009). Autodock Tools (ADT) was used to optimize the receptor and ligand molecules. For preparation of the receptor molecule, polar hydrogens, Kollman charges and AD4 type of atoms were added, while Gasteiger charges were added on the ligands and maximum numbers of active torsions were given. AutoGrid4 was used to prepare a grid map of interaction energies around LEU 263, PHE 264, GLN 267, ILE 977, ILE 981, ALA 985, ASN 1039, LEU 1040, ILE 1041 and ASN 1042 with a grid box of 90 X 90 $\mathrm{X} 90 \AA$ Á 3 centered on $\mathrm{X}, \mathrm{Y}, \mathrm{Z}=52.27,16.45,11.48$ with a grid spacing of $0.375 \AA$. The residues used in the current 
study have been considered and validated as the binding pocket of PfATP6 as per earlier reports (Jung et al., 2005; Garah et al., 2009; Shandilya et al., 2013). Molecular docking was performed using Lamarckian Genetic Algorithm (LGA), keeping the receptor molecule rigid throughout the docking simulation and rest of the docking parameters was set to default values. Ten different poses were generated for each ligand and scored using AutoDock 4.2 scoring functions and were ranked according to their docked energy. AutoDock Tools, PyMOL (Delano, 2002; Lerner, Carlson, 2008) and LigPlot+ (Laskowski, Swindells, 2011) were used for post docking analysis.

\section{Chemicals and reagents}

Curcumin (80\%), artemisinin (98\%), piperidine and benzaldehyde groups used for synthesis were obtained from Sigma Aldrich. Methanol used as a reaction medium was obtained from Qualigens. Sodium hydrogen phosphate, dichloromethane used in column chromatography and petroleum benzine, chloroform used in purification and recrystallization process were obtained from Spectrochem. All the chemicals used were of analytical grade. The chemicals used in the continuous malaria culture and antimalarial drug testing such as RPMI, sodium bicarbonate, D-sorbitol and DMSO were obtained from Sigma Aldrich. Plasma and O +ve blood were obtained from a voluntary donor.

\section{Chemistry}

Curcumin obtained from Sigma was further purified and separated from its demethoxy and bis-demethoxy analogs by column chromatography using Silica gel impregnated with sodium hydrogen phosphate as the solid phase and dichloromethane as the eluent (Almeida et al., 2005). Synthesis of curcumin derivatives was based on a method to similar to the one used by Padhye and his coworkers (2009). Curcumin (0.01 mol) was dissolved in an adequate amount of methanol in small portions with continuous stirring. The aryl benzaldehyde groups ( 0.01 mol) were dissolved separately in a minimum amount of methanol. The benzaldehyde mixture is added drop wise to the curcumin solution with constant stirring. Using a pilot study, it was determined that the requirement of piperidine as a catalyst does not exceed $5 \%$. The reaction mixture was stirred for 48 hours and the progress of the reaction periodically monitored using TLC (toluene:methanol) (Figure 3). After the stipulated time, the reaction mixture is kept overnight at $4{ }^{\circ} \mathrm{C}$ for product separation. The supernatant liquid is allowed to evaporate at room temperature. The product is extracted using a mixture of dichloromethane and water, washed repeatedly with petroleum benzine and recrystallized with chloroform to yield required products with good yields.
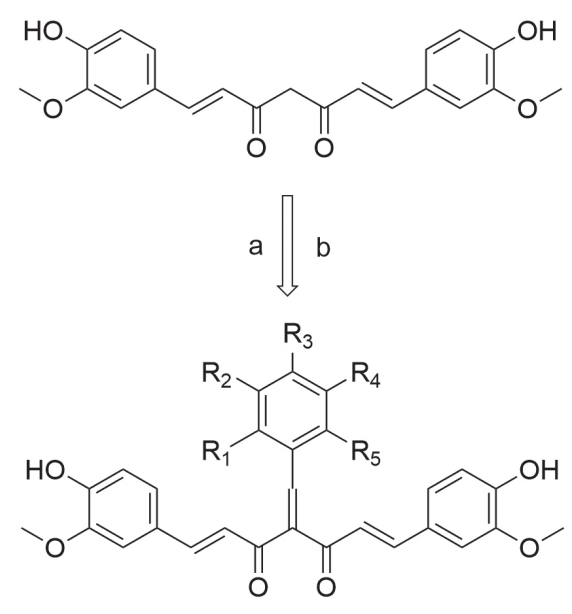

FIGURE 3 - Reaction scheme: Synthesis of Knoevenagel condensates of curcumin. Reagents and conditions: (a) Salicylaldehyde, 4-methoxybenzaldehyde, 3-hydroxybenzaldehyde, benzaldehyde, 2,3-dichlorobenzaldehyde, 4-fluorobenzaldehyde, paranitrobenzaldehyde, 4-methylbenzaldehyde; (b) Methanol, piperidine ( $<5 \%), 48 \mathrm{~h}$.

\section{Preparation of parasites}

The sensitive 3D7 strain of $P$. falciparum was routinely maintained in stock cultures in a RPMI1640 medium supplemented with 25 mmol HEPES, $1 \%$ D-glucose, $0.23 \%$ sodium bicarbonate and $10 \%$ heat inactivated human plasma (Trager, Jensen, 1976). The asynchronous parasites of $P$. falciparum were synchronized after $5 \%$ D-sorbitol treatment to obtain only the ring stage of the parasite. For carrying out the assay, the initial ring stage parasitaemia was maintained at $1 \%$ and $3 \%$ haematocrit.

\section{In vitro antimalarial screening}

The in vitro schizonticidal activity test was carried out according to the WHO Mark III protocol and the microassay methods of Reickmann and Desjardins with minor modifications (World Health Organisation, 2001; Rieckmann et al., 1978; Desjardins et al., 1979). The compounds were dissolved in 1:200 dimethyl sulfoxide (DMSO) to get a stock solution of $5 \mathrm{mg} / \mathrm{ml}$ concentration. The further required dilutions of the stocks were prepared with IRPMI. To a 96-well flat bottom microtitre plate 20 microliters of the test compounds of the secondary 
standard curcumin and different test dosages were charged per well in duplicates and accordingly 180 microliters of synchronized parasites in 3\% hematocrit containing $1 \%$ parasitaemia was added to get the final test dose. Artemisinin as a primary standard was used for this test to validate the integrity of the assay. The negative control wells inoculated with $20 \mu \mathrm{L}$ of CRPMI to which 180 $\mu \mathrm{L}$ of $3 \%$ hematocrit with $1 \%$ parasitaemia were added. The plates were incubated for $24 \mathrm{~h}$ in a water jacketed incubator at $37^{\circ} \mathrm{C}$ and $5 \% \mathrm{CO}_{2}$ environment, after which thin blood smears were prepared from each well, fixed with methanol, stained with $3 \%$ Giemsa and observed under microscope. The number of schizonts (having more than 3 nuclei) was counted per 200 asexual parasites and their inhibition percentage was calculated according to the formula

$\%$ of Schizont Inhibition $=($ Control - Treated $/$ Control $) \times 100$

\section{Ligands drug likeness, bioavailability and ADMETox}

The ligand library was passed through FAFDrugs3 (http://fafdrugs2.mti.univ-paris-diderot.fr/) for computational screening of drug likeness, bioavailability, undesirable moieties and Pan Assay Interference Compounds (PAINS). The drug likeness was analyzed as per Lipinski's rule of 5 and bioavailability was estimated as "good" or "bad" according Egan and Veber's rule (Egan, Merz, Baldwin, 2000; Veber et al., 2002). FAF-Drugs3 depicts the undesirable moieties as warheads (Rishton, 1997; Rishton, 2003), frequent hitters (Roche et al., 2002), promiscuous inhibitors (Mcgovern et al., 2002), flagged or intermediate substructure as per medicinal chemistry. According to Baell and his co-workers. (Baell et al., 2010), PAINS are compounds that appear as frequent hitters (promiscuous compounds) that tend to be false positive. Furthermore, PreADMET (http://preadmet.bmdrc.org/) server was used to determine mutagenicity (Ames test) (Ames et al., 1972), Blood Brain Barrier (BBB) (Ma, Chen, Yang, 2005), Plasma Protein Binding (PPB) and Human Intestinal Absorption (HIA) (Yee, 1997) properties of the selected compounds.

\section{RESULTS}

Docking studies against PfATP6 showed 4-FB to have slightly higher binding energy to standard artemisinin (-6.75 and -6.73 respectively)(Figures 4 and 5) while 4-MB, 3-HB, 4-FB, B, 4-NB displayed better binding energy against the secondary standard curcumin $(-5.95,-5.89,-5.68$, $-5.35,-5.29$ and -5.25 respectively). In vitro screening of the compounds at $50 \mu \mathrm{g} / \mathrm{mL}$ concentration showed $100 \%$ schizont inhibition in all the six compounds (Figure 6). At $5 \mu \mathrm{g} / \mathrm{mL}$ concentration, five showed more than $75 \%$ inhibition and better results than curcumin while 4-FB showed the best activity. The in vitro results validate the results obtained from in silico study. To affirm the in silico protocols, two negative controls 2, 3-DCLB and 4-MEOB with low binding energy $(+21.87,+1.48$ respectively), were synthesized and tested for their in vitro activity. The results obtained at $5 \mu \mathrm{g} / \mathrm{mL}$ concentration $(13.43,24.77 \%$ schizont inhibition respectively) confirms efficacy of the docking protocol. They, however, showed $100 \%$ inhibition at a dose

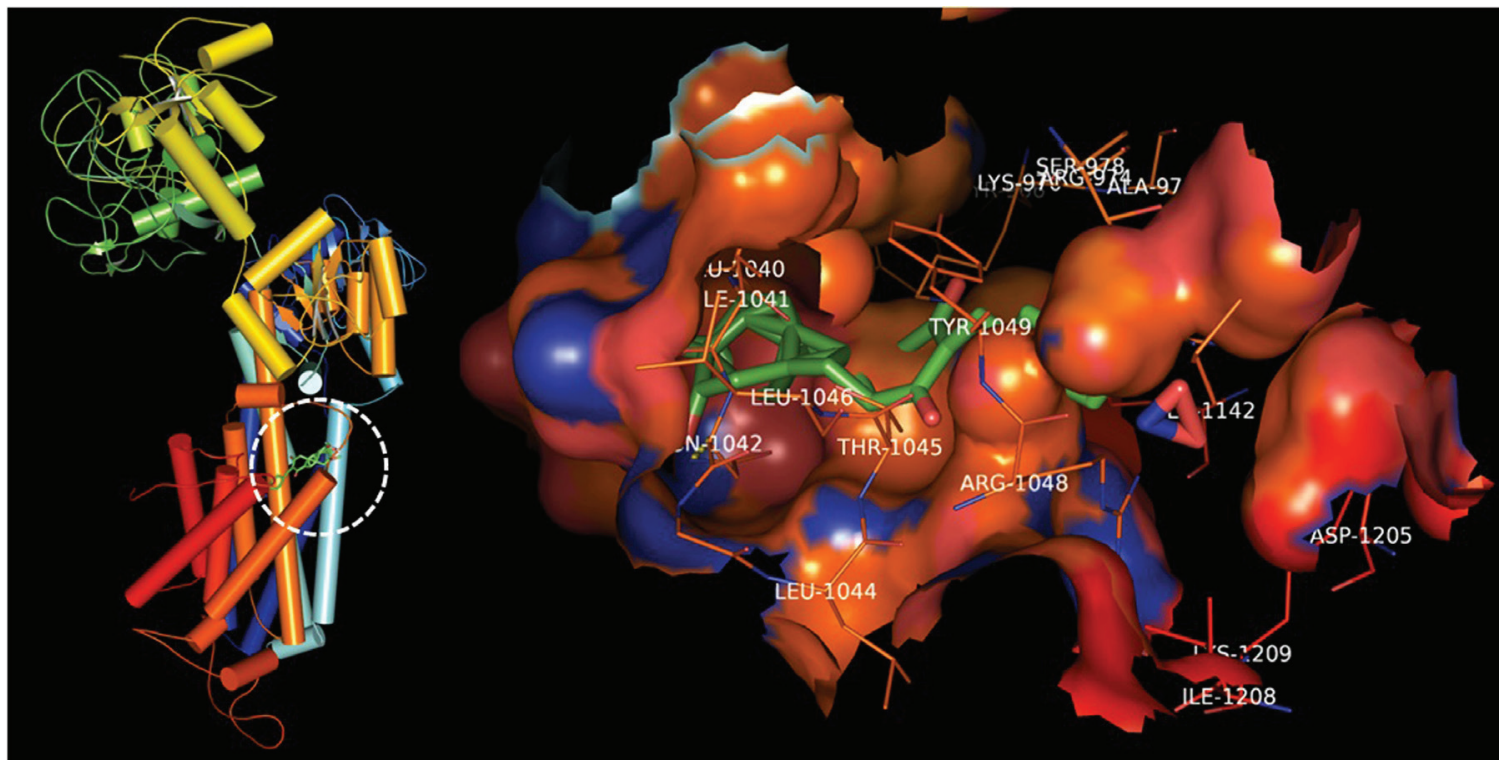

FIGURE 4 - Artemisin docked complex. 


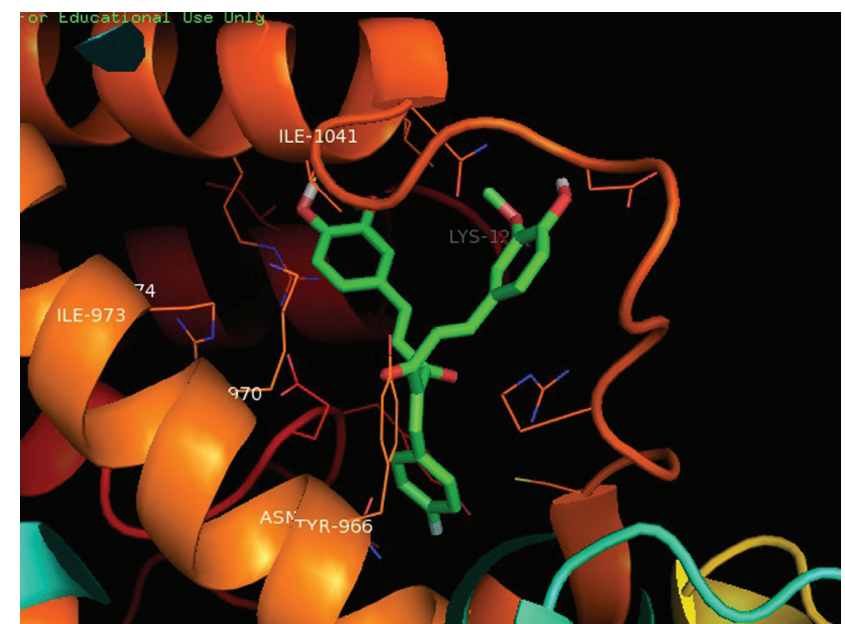

FIGURE 5 - 4-FB docked complex.

of $50 \mu \mathrm{g} / \mathrm{mL}$ indicating a requirement of higher dosage to produce its inhibitory activity (Table II).

Table III shows the ADME and toxicity profiles of the compounds which were analyzed using PreADMET and FAFdrugs 3 online software. Of the 32 compounds two, 4-H 3,5-DMB and 3-NB showed positive for Ames mutagenicity test. The total polar surface area (tPSA) values of 29 compounds remained below $140 \AA$, which suggested good cell permeability capacity. Two compounds, 2,4-DNB and 3,4,5-THB had tPSA values in excess of $140 \AA$ suggesting poor cell permeability.
According to oral bioavailability rules (Egan's and Veber's rules), all the compounds fulfilled the required parameters as evident by the positive results. 4 compounds (2,3-DCLB, 2,4-DNB, 2,5-DMEOB, 4-MTB) violated more than 1 Lipinsky rules. Compounds 2,3-DCLB; 2,4,6-TMB; 2,4,5-TMB; 4-H,3,5-DMB; 4-ISOB showed slightly high Blood Brain Barrier (BBB) penetration values $(2.32,2.64,2.61,2.87,2.08$ respectively). Apart from 2,4-DNB the rest of the selected compounds showed significant plasma protein binding values. Compounds 4-NB and 2, 4-DNB showed $54.07 \%$ and $14.41 \%$ human intestinal absorption respectively while the rest showed above $80 \%$ absorption.

\section{EXPERIMENTAL}

\section{General methods}

Melting points were measured with a Buchi B-540 melting point apparatus and are uncorrected. IR spectra were recorded on Bruker ALPHA FT-IR spectrometer on a thin film using chloroform. ${ }^{13} \mathrm{C}$ and ${ }^{1} \mathrm{H}$ NMR spectra were recorded on Bruker Avance II 400-NMR spectrometer using tetramethylsilane (TMS) as an internal standard. Mass spectra were recorded on Waters, Q-TOF micromass (ESI-MS) spectrometer. All the commercially available reagents were used as received. All experiments were
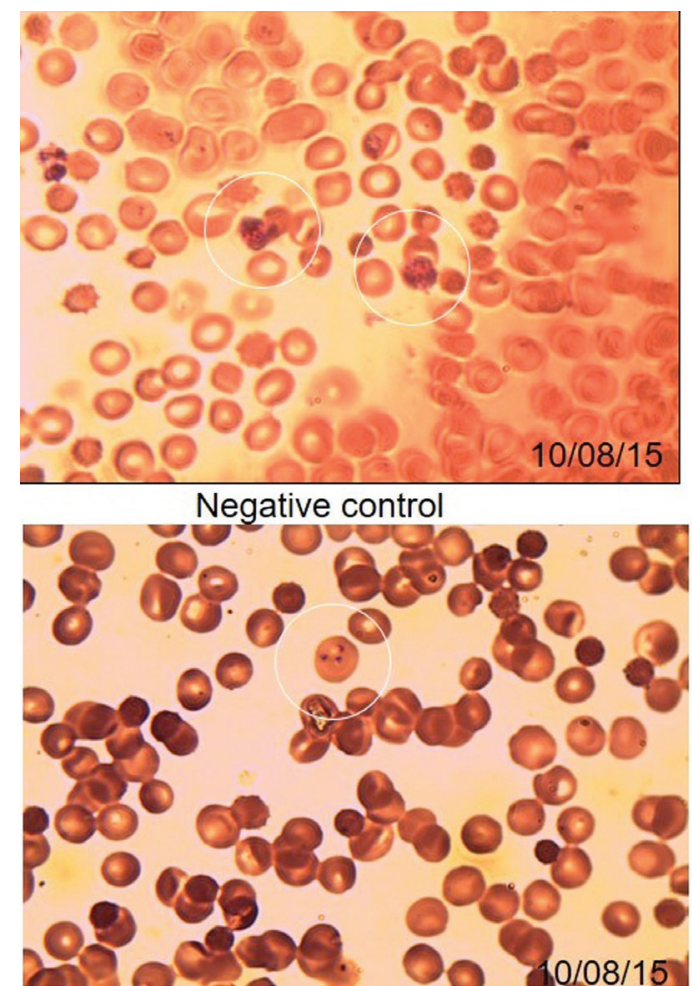

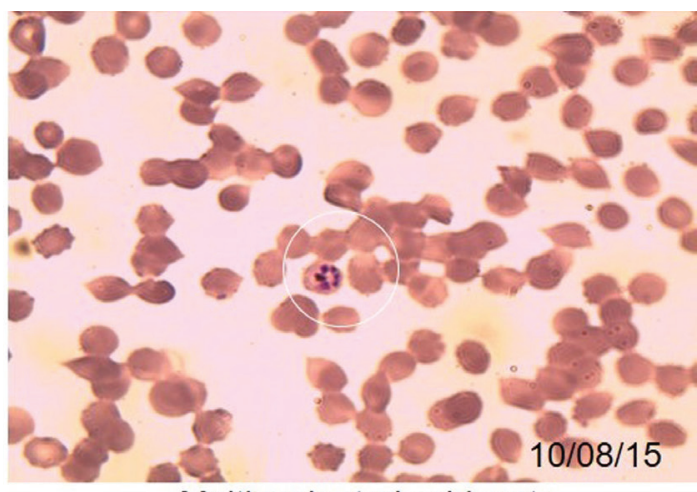

Multinucleated schizonts

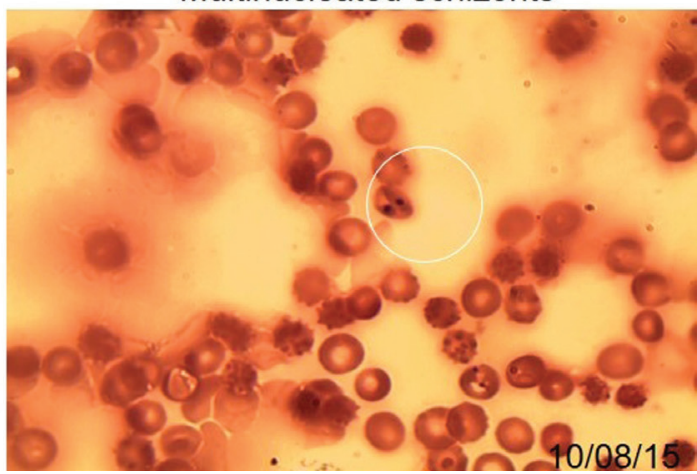

FIGURE 6 - Drug treated parasite morphology. 
TABLE II - Free energy of binding and in vitro screening results

\begin{tabular}{|c|c|c|c|c|}
\hline \multirow{2}{*}{ SI No. } & \multirow{2}{*}{ Compound na name } & \multirow{2}{*}{$\begin{array}{c}\text { Free energy of binding } \\
(\mathrm{kcal} / \mathrm{mol})\end{array}$} & \multicolumn{2}{|c|}{ \% Schizont Inhibition } \\
\hline & & & $5 \mu \mathrm{g} / \mathrm{mL}$ & $50 \mu \mathrm{g} / \mathrm{mL}$ \\
\hline 1. & 4-FB & -6.75 & 97.8 & 100 \\
\hline 2. & ARTEMISININ & -6.73 & 100 & 100 \\
\hline 3. & 4-MB & -5.95 & 93.1 & 100 \\
\hline 4. & $3-\mathrm{HB}$ & -5.89 & 89.5 & 100 \\
\hline 5. & 2-HB & -5.68 & 82.7 & 100 \\
\hline 6. & $\mathrm{~B}$ & -5.35 & 80.1 & 100 \\
\hline 7. & $4-\mathrm{NB}$ & -5.29 & 79.9 & 100 \\
\hline 8. & CURCUMIN & -5.25 & 79.6 & 100 \\
\hline 9. & $3-\mathrm{NB}$ & -4.29 & & \\
\hline 10. & 4-ISOPB & -4.27 & & \\
\hline 11. & $3,4,5-\mathrm{THB}$ & -4.22 & & \\
\hline 12. & 2,4-DMB & -4.17 & & \\
\hline 13. & 4-H,3,5-DMB & -4.15 & & \\
\hline 14. & $4-\mathrm{HB}$ & -3.87 & & \\
\hline 15. & 3,4-DMB & -3.82 & & \\
\hline 16. & 4-H,3-MEOB & -3.17 & & \\
\hline 17. & $2,4,5-\mathrm{TMB}$ & -1.82 & & \\
\hline 18. & 2,5-DMEOB & -1.82 & & \\
\hline 19. & 3-MEOB & -1.81 & & \\
\hline 20. & 2,4-DHB & -1.79 & & \\
\hline 21. & 4-EOB & -1.79 & & \\
\hline 22. & 2,4,6-TMB & -1.78 & & \\
\hline 23. & 4-EB & -1.75 & & \\
\hline 24. & 2,3-DCLB & +21.87 & 13.43 & 100 \\
\hline 25. & 4-MEOB & +1.48 & 24.77 & 100 \\
\hline 26. & 3,4-DFB & +20.57 & & \\
\hline 27. & 3-F,4-MB & +8.28 & & \\
\hline 28. & 3-F,2-MB & +8.28 & & \\
\hline 29. & 4-CNB & +20.72 & & \\
\hline 30. & $4-\mathrm{AB}$ & +25.29 & & \\
\hline 31. & 4-DMAB & +16.15 & & \\
\hline 32. & 4-CLB & +32.57 & & \\
\hline 33. & 2,4-DNB & +2.09 & & \\
\hline 34. & 4-MTB & +25.62 & & \\
\hline
\end{tabular}

monitored by thin layer chromatography (TLC). TLC was performed on prepared silica glass plates. Column chromatography was performed on silica gel (60-120 mesh, Merck Chemicals).

(1E,6E)-4-(4-fluorobenzylidene)-1,7-bis(4hydroxy-3-methoxyphenyl)hepta-1,6-diene-3,5-dione
(4-FB): TLC: toluene/methanol (4:1). $\mathrm{Rf}=0.57$, yield: 76\%, mp: 96-98 ${ }^{\circ} \mathrm{C}$. IR ( $\left.\mathbf{c m}^{-1}\right): 3636,1684,1656,1260$. ${ }^{1} \mathbf{H}$ NMR (CDCl $\left.\mathbf{3}, \mathbf{4 0 0} \mathbf{M H z}\right): \delta 9.81(\mathrm{~s}, 1 \mathrm{H}), 7.40(\mathrm{~m}, 2 \mathrm{H})$, $7.11(\mathrm{~d}, 2 \mathrm{H}), 6.99(\mathrm{~d}, 2 \mathrm{H}), 7.72(\mathrm{~m}, 2 \mathrm{H}), 6.79(\mathrm{~m}, 2 \mathrm{H}), 3.83$ (s, 6H), $8.48(\mathrm{~d}, 2 \mathrm{H}), 7.82(\mathrm{~d}, 2 \mathrm{H}), 7.03(\mathrm{~d}, 2 \mathrm{H}) .{ }^{13} \mathbf{C}$ NMR $\left(\mathbf{C D C l}_{3}, 400 \mathrm{MHz}\right): 162.1,149.7,144.9,127.6,128.54$, 


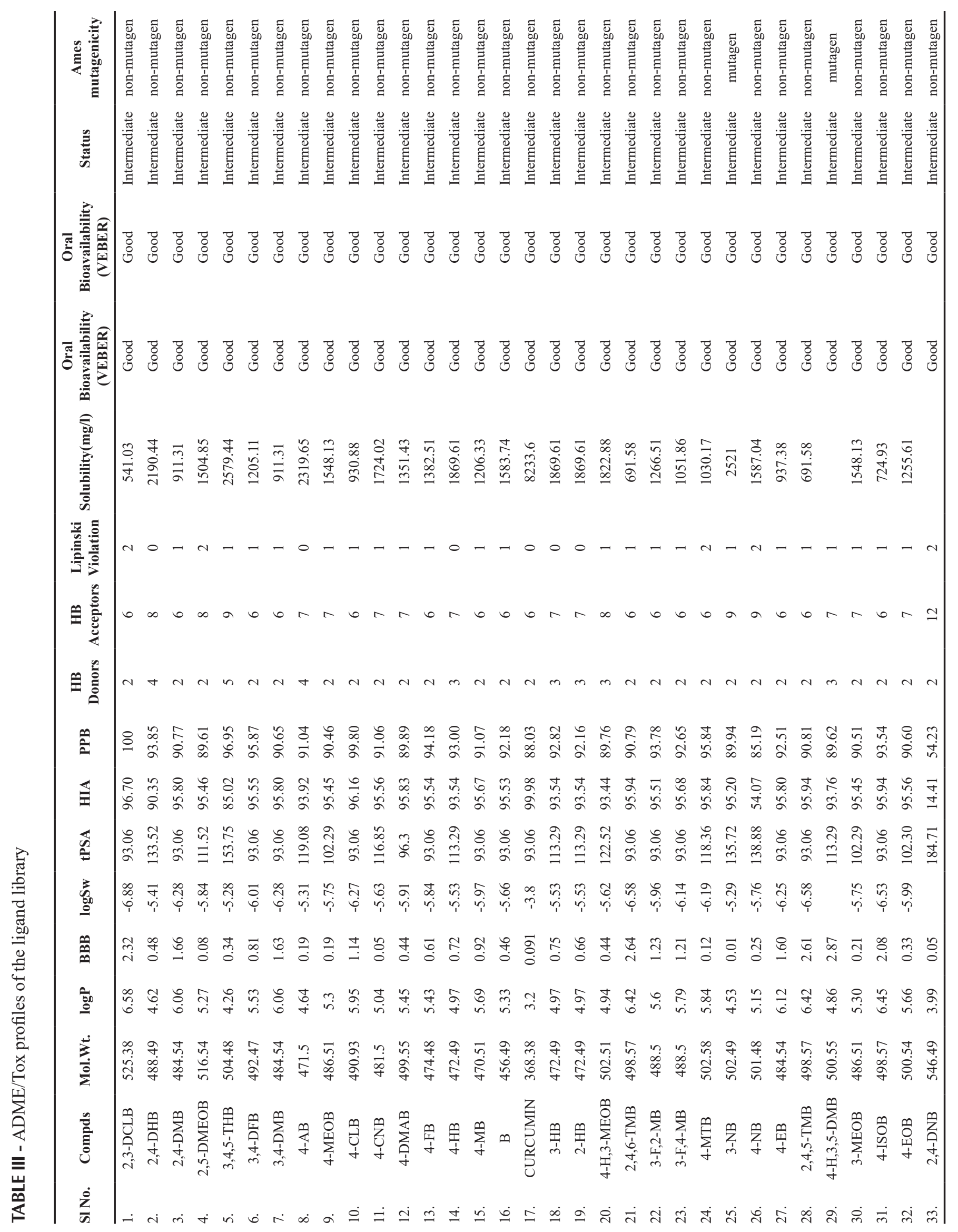


$115.4,111.9,116.8,130.4,122.9,116.8,183.7,59.1$ 165.8, 142.2, 146.9, 125.4. MS (EI, m/z): $474(\mathrm{M}-60+)$.

(1E,6E)-1,7-bis(4-hydroxy-3-methoxyphenyl)4-(2-hydroxybenzylidene) hepta-1,6-diene-3,5-dione (2-HB): TLC: toluene/methanol (9:1). $\mathrm{Rf}=0.60$, yield: 65\%, mp: 93-96 ${ }^{\circ} \mathrm{C}$. IR ( $\left.\mathbf{c m}^{-1}\right): 3645,1700,1645,1250$. ${ }^{1} \mathrm{H}$ NMR (CDCl $\left.{ }_{3}, \mathbf{4 0 0} \mathbf{M H z}\right): \delta 9.43$ (s, $\left.1 \mathrm{H}\right), 10.27$ (s, $1 \mathrm{H}), 7.22(\mathrm{~d}, 2 \mathrm{H}), 7.10(\mathrm{~d}, 2 \mathrm{H}), 6.72(\mathrm{~m}, 2 \mathrm{H}), 6.85(\mathrm{~d}$, 2H), $7.49(\mathrm{~d}, 2 \mathrm{H}), 7.06(\mathrm{~d}, 2 \mathrm{H}), 6.90(\mathrm{~d}, 2 \mathrm{H}), 3.83(\mathrm{~s}, 3 \mathrm{H})$, $7.82(\mathrm{~d}, 2 \mathrm{H}), 7.03(\mathrm{~d}, 2 \mathrm{H}) \cdot{ }^{13} \mathbf{C} \mathbf{N M R}\left(\mathbf{C D C l}_{3}, \mathbf{4 0 0} \mathbf{M H z}\right)$ : $\delta 149.1,147.9,157.1,120.0,127.6,111.9,116.8,117.6$, $122.9,132.9,129.3,121.2,183.7,55.1 . \mathrm{MS}(\mathrm{EI}, \mathrm{m} / \mathrm{z})$ : $472(\mathrm{M}-60+)$.

(1E,6E)-1,7-bis(4-hydroxy-3-methoxyphenyl)4-(4-methylbenzylidene) hepta-1,6-diene-3,5-dione (4-MB): TLC: toluene/methanol (7:3). $\mathrm{Rf}=0.58$, Yield: 59\%, mp: 82-87 ${ }^{\circ} \mathrm{C}$. IR ( $\left.\mathbf{c m}^{-1}\right): 3639,1695,1659,1240$. ${ }^{1} \mathbf{H}$ NMR (CDCl $\left.\mathbf{3}, \mathbf{4 0 0} \mathbf{M H z}\right): \delta 9.49(\mathrm{~s}, 1 \mathrm{H}), 7.11(\mathrm{~d}, 2 \mathrm{H})$, $6.99(\mathrm{~d}, 2 \mathrm{H}), 6.79(\mathrm{~d}, 2 \mathrm{H}), 7.59$ (d, 2H), 7.39 (d, 2H), 3.83 $(\mathrm{s}, 3 \mathrm{H}), 2.41(\mathrm{~s}, 3 \mathrm{H}), 8.48(\mathrm{~s}, 1 \mathrm{H}), 7.82(\mathrm{~d}, 2 \mathrm{H}), 7.03(\mathrm{~d}, 2 \mathrm{H})$. ${ }^{13} \mathbf{C}$ NMR (CDCl $\mathbf{3}, \mathbf{4 0 0}$ MHz): $\delta 150.2,146.8,127.6,129.9$, 137.6, 109.9, 122.9, 134.4, 128.9, 183.7, 59.1, 165.8, 142.2, 21.3, 145.9, 123.4. MS (EI, m/z): 470 (M-60+).

(1 E,6E)-4-benzylidene-1,7-bis(4-hydroxy-3methoxyphenyl)hepta-1,6-diene-3,5-dione (B): TLC: Toluene/Methanol (7:1). Rf $=0.63$, yield: $53 \%$, mp: 118 $121{ }^{\circ} \mathrm{C}$. IR $\left(\mathbf{c m}^{-1}\right): 3646,1687,1651,1249 .{ }^{1} \mathbf{H}$ NMR (CDCl ${ }_{3}, 400$ MHz): $\delta 9.55$ (s, 1H), $7.44(\mathrm{~d}, 2 \mathrm{H}), 6.99$ (d, $2 \mathrm{H}), 7.11(\mathrm{~d}, 2 \mathrm{H}), 6.79(\mathrm{~d}, 2 \mathrm{H}), 7.60(\mathrm{~d}, 2 \mathrm{H}), 7.39(\mathrm{~d}, 2 \mathrm{H})$, $7.33(\mathrm{~d}, 2 \mathrm{H}), 3.83(\mathrm{~s}, 3 \mathrm{H}), 8.48(\mathrm{~s}, \mathrm{H}), 7.82(\mathrm{~d}, 2 \mathrm{H}), 7.03$ $(\mathrm{d}, 2 \mathrm{H}) .{ }^{13} \mathbf{C}$ NMR $\left(\mathbf{C D C l}_{3}, \mathbf{4 0 0} \mathbf{M H z}\right): \delta 149.8,145.9$, 128.2, 132.6, 110.9, 116.8, 122.9, 129.5, 128.6, 127.9, 183.7, 55.3, 165.8, 142.2, 146.9, 123.4. MS (EI, m/z): $456(\mathrm{M}-60+)$.

(1E,6E)-1,7-bis(4-hydroxy-3-methoxyphenyl)4-(3-hydroxybenzylidene) hepta-1,6-diene-3,5-dione (3-HB): TLC: toluene/methanol (8:1). $\mathrm{Rf}=0.61$ Yield: 63\%, mp: 79-81 ${ }^{\circ} \mathrm{C}$. IR ( $\left.\mathbf{c m}^{-1}\right): 3642,1695,1643,1251$. ${ }^{1} \mathrm{H}$ NMR (CDCl $\left.{ }_{3}, \mathbf{4 0 0} \mathbf{M H z}\right): \delta 9.61(\mathrm{~s}, 1 \mathrm{H}), 9.45(\mathrm{~s}, 1 \mathrm{H})$, $7.11(\mathrm{~d}, 2 \mathrm{H}), 6.99(\mathrm{~d}, 2 \mathrm{H}), 6.83(\mathrm{~d}, 2 \mathrm{H}), 6.70(\mathrm{~s}, 1 \mathrm{H}), 6.79$ $(\mathrm{d}, 2 \mathrm{H}), 7.16(\mathrm{~d}, 2 \mathrm{H}), 7.31(\mathrm{~d}, 2 \mathrm{H}), 3.83(\mathrm{~s}, 3 \mathrm{H}), 8.48(\mathrm{~s}, \mathrm{H})$, $7.82(\mathrm{~d}, 2 \mathrm{H}), 7.03(\mathrm{~d}, 2 \mathrm{H}) .{ }^{13} \mathbf{C ~ N M R}\left(\mathbf{C D C l}_{3}, \mathbf{4 0 0} \mathbf{M H z}\right)$ : $\delta$ 150.2 147.1, 158.4, 135.6, 124.6, 110.5, 116.8, 115.1, $112.1,122.9,121.9,130.0,183.7,56.1,165.8,142.2$, 146.9, 125.4. MS (EI, m/z): 472 (M-60+).

(1E,6E)-1,7-bis(4-hydroxy-3-methoxyphenyl)-4(4-nitrobenzylidene)hepta-1,6-diene-3,5-dione (4-NB): TLC: toluene/methanol (5:1). Rf $=0.49$, Yield: $70 \%$, mp: 104-106 ${ }^{\circ} \mathrm{C}$. IR ( $\left.\mathbf{c m}^{-1}\right): 3639,1682,1647,1244 .{ }^{1} \mathbf{H}$ NMR (CDCl ${ }_{3}, 400$ MHz): $\delta 9.55(\mathrm{~s}, 1 \mathrm{H}), 7.11(\mathrm{~d}, 2 \mathrm{H}), 6.99(\mathrm{~d}$, $2 \mathrm{H}), 8.37(\mathrm{~d}, 2 \mathrm{H}), 6.79(\mathrm{~d}, 2 \mathrm{H}), 8.03(\mathrm{~d}, 2 \mathrm{H}), 6.99(\mathrm{~d}, 2 \mathrm{H})$, $3.83(\mathrm{~s}, 3 \mathrm{H}), 8.62(\mathrm{~s}, 1 \mathrm{H}), 7.82(\mathrm{~d}, 2 \mathrm{H}), 7.03(\mathrm{~d}, 2 \mathrm{H}) .{ }^{13} \mathrm{C}$ NMR (CDCl ${ }_{3}, 400$ MHz): $\delta$ 151.1, 148.2, 146.7, 126.6, 139.0, 112.8, 115.8, 122.8, 120.9, 133.2, 184.7, 58.1, 164.8, 141.2, 145.9, 124.4. MS (EI, m/z): 501 (M-60+).

\section{DISCUSSION}

Artemisinin has long been the backbone of antimalarial studies but of late concerns over its resistance in south-east Asian countries and Greater Mekong areas have led to newer combinations of antimalarial agents being employed. Failure in rapid clearance of parasites compromises the use of artemisinin for the treatment of severe malaria, which in turn leads to an increased risk of resistance coupled with treatment failure. As a result of which newer antimalarial agents with substantial activity and less toxicity are the need of the hour. Studies have shown that PfATP6 protein, the major target of artemisinin is also a molecular drug target of curcumin obtained from Curcuma longa. The efficacy of curcumin as an antimalarial agent has already been established (Cheng et al.., 2001). Moreover, curcumin has been found to be nontoxic in nature over very high doses (Hatcher et al.., 2008). The study was thereby undertaken to assess the antimalarial activity of curcumin derivatives considering PfATP6 as the drug target and was principally aimed at correlating the in silico docking outcome with in vitro anti malarial screening results in order to develop a series of curcumin derivatives with cogent antimalarial activity. 4-FB emerged as the best dock compound among the selected compounds with better binding energy than artemisinin and curcumin. At a dosage of $5 \mu \mathrm{g} / \mathrm{ml} 4$-FB inhibited $97.8 \%$ schizonts as compared to $100 \%$ inhibition by artemisinin which indicated its high schizonticidal activity. Similarly, 2-HB, 4-MB, 3-HB, 4-FB, B showed higher binding potential than curcumin and better inhibitory action against $P f$ cultures as evidenced through in vitro assay. While only eight compounds were synthesized, the binding energies of 3-NB, 4-ISOB, 2, 4-DMB, 4-HB, 3,4-DMB, 3,4,5-THB, 4-H-3,5-DMB, 4-H,3-MEOB showed promising results and are likely to be synthesized and screened for in vitro antimalarial activity.

In silico ADME/Tox study provided substantial information about the selected compounds regarding their pharmacokinetic and toxicity profiles. 32 compounds along with the secondary standard curcumin were screened for their pharmacokinetic, pharmacodynamic and toxicity properties.

Blood Brain Barrier (BBB) Penetration is the capacity of a compound to penetrate the endothelial cells in CNS vessels that usually restricts the passage of 
solutes. 2,3-DCLB; 2,4,6-TMB; 2,4,5-TMB; 4-H,3,5DMB; 4-ISOB showed slightly high BBB penetration values $(2.32,2.64,2.61,2.87,2.08$ respectively) which led to the rejection of the candidates as prospects of drug development.

Plasma protein binding of a drug influences not only on the drug's action but also its disposition and efficacy as only the unbound drug is available for diffusion or transport across cell membranes, and interaction with a pharmacological target. Through PreADMET predictions it was observed that all the compounds except 2,4-DNB demonstrated a considerable amount of binding to the plasma proteins, indicating improved attachment to the target site.

Ames test determines the mutagenicity of a compound using several strains of the bacterium Salmonella typhimurium that carry mutations in genes involved in histidine synthesis. The variable being tested is the mutagen's ability to cause a reversion to growth on a histidine-free medium (Ames et al.., 1972). TA98, TA100 and TA1535 strains are used in PreADMET toxicity predictions which are often used in Ames test. The results can be estimated both with the application of metabolite (Metabolic activation by rat liver 10\% homogenate, + S9) and without application of the metabolite (No metabolic activation, -S9). Among the selected compounds only 3 -NB showed chances of mutating while the rest were classified as nonmutagens.

Predicting human intestinal absorption of drugs is an important criterion for identifying potential drug candidates. It is considered the sum of bioavailability and absorption evaluated from ratio of cumulative excretion in urine, bile and feces (Yee, 1997). Through PreADMET analysis it was observed that out of the selected compounds 4-NB and 2, 4-DNB showed poor intestinal absorption than the rest indicating a lower rate of absorption of nitrogen containing compounds.

\section{Structure activity relationship}

The phenolic groups in the curcumin nucleus are generally considered for exerting their antimalarial activity. Any change in these groups has been reported to have decreased the antimalarial efficacy of the compound (Mishra et al., 2008). Any changes in the parent molecule thereby would have to be made either by condensing the diketo groups or attacking the active methylene bridge of the curcumin scaffold. The latter step was chosen, and the active methylene bridge was targeted with aryl benzaldehydic groups through Knoevenagel condensation and the results were analyzed to determine increase/decrease in antimalarial activity as compared to the parent molecule.
A detailed SAR analysis revealed important structural points responsible for variation in antimalarial activity. A fluorine group in the para position of the substituent increases activity of the compound. The presence of a hydroxyl group enhances the activity of the compound as evidenced by its binding energy and schizonticidal activity (2-HB, 3-HB). Apart from the synthesized compounds, 4-HB, 3,4,5-THB, 2,4-DHB also showed fair binding energies, thereby validating the theory. The position of the hydroxyl group in the compound does not produce any large scale differences to the results. Increasing the number of hydroxyl groups decreases the score of the compounds, which can be attributed to steric hindrance. A nitro group at the para and meta position shows moderate activity. Toxicity and plasma protein binding capacities of nitro group compounds appear to be governed by the number and position of the nitro substituents. The addition of a methyl group augments the activity of the compound. Electron donating groups enhance the activity of the compounds. Increase in the number of nitro and halogen substituent's leads to a decrease in the binding energy which can be associated to the bulkiness of the compound leading to steric hindrance. As can be seen from Figures 7 and 8 using LigPlus, both artemisinin and the synthesized curcumin derivatives were observed to fit in the exact docking pocket (Lys 1213, Leu 1044, Asn 1042, Tyr 966, Thr 1045, Lys 970, Arg 1034, Asn 967, Glu 1142) through a series of hydrophilic and hydrophobic interactions. The methoxy oxygen in the $3^{\text {rd }}$ position of 4-FB (bond length $2.65 \AA$ ) and the keto group of artemisinins (bond length $2.83 \AA$ ) both show a strong hydrogen bonded interaction with the Lys 1213 residue of PfATP6. This asserts the fact that the methoxy and hydroxyl groups of the phenolic ring systems in the curcumin molecule are required for proper binding to the PfATP6 protein. Spikes indicate favorable hydrophobic interactions between 4-FB and PfATP6 which conclude that hydrophobic force is the main interaction force in the binding of the curcumin derivatives to the PfATP6 protein. Analogous binding site of curcumin and artemisinin enabled us to consider artemisinin as the primary standard for our study. The enhanced properties of the compounds maybe attributed to stronger binding affinities of the designed compounds to the PfATP6 protein then the parent molecule. Further in vivo studies would be required to determine the efficacy of the compounds, their toxicities and the effect of biotransformation on the compounds. Though there are reports on in silico studies of curcumin on PfATP $6{ }^{24}$ as well as the synthesis of different curcumin analogues/derivatives (Manohar et al., 2013; Mishra et al., 2008; Sahu et al., 2012; Zambre et al., 2007; Padhye et al., 2009; Liang et al., 2009; Selvam et al., 
2005; Ali et al., 2013) the two have not been interlinked in relation to antimalarial in vitro studies. The originality of

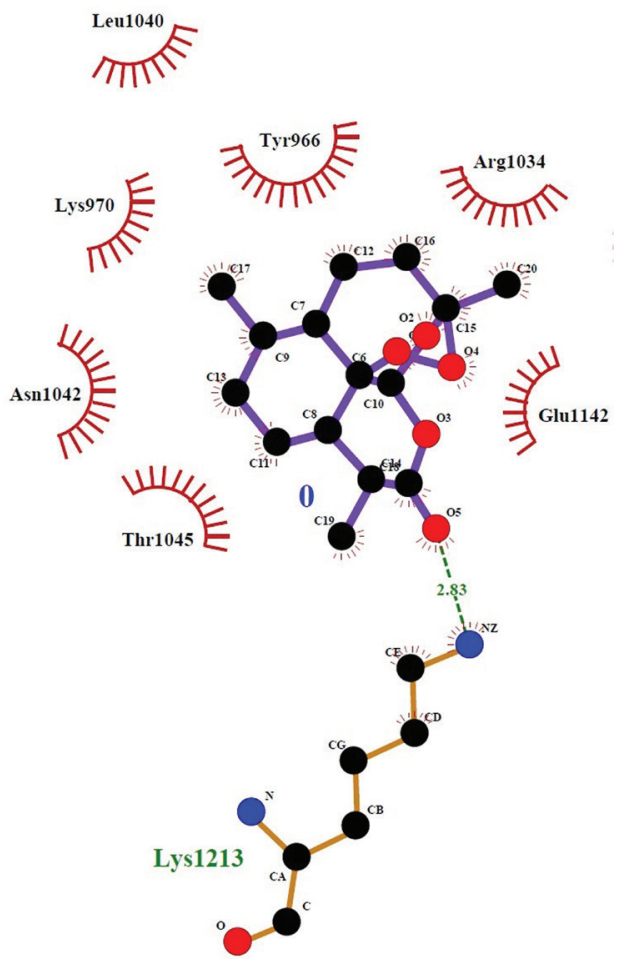

FIGURE 7 - Artemisinin docking pocket.

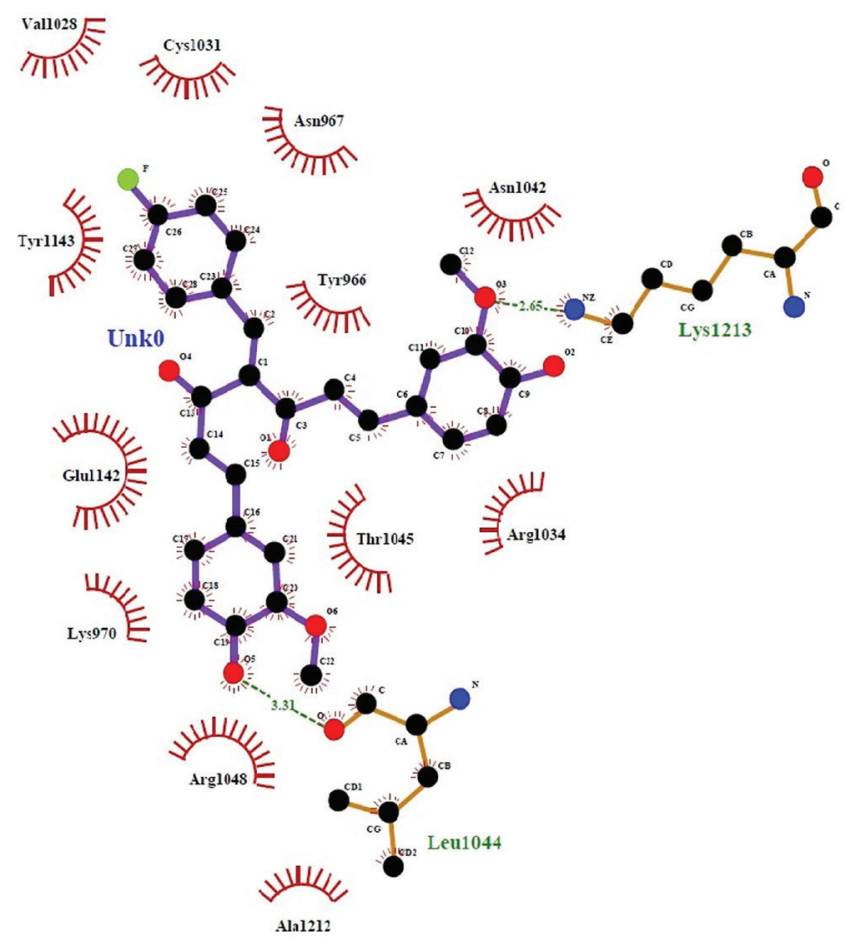

$1 \mathrm{u} 5 \mathrm{n}$

FIGURE 8 - 4-FB docking pocket. the work lies in the fact that design and in silico studies on an entire series of Knoevenagel condensates of curcumin and their correlation with in vitro antimalarial activity have been discussed for the first time.

\section{CONCLUSION}

The high binding energy of the synthesized derivatives showed that the designed curcumin analogues have good affinities for the PfATP-6 protein which is likely to be the reason for its significant antimalarial activity against the Plasmodium falciparum species. Though this might not be the only way in which the compounds act against the parasites, it paves the way for future molecular level studies to ascertain the mechanism. The study is likely to provide valuable insight and in-depth assessment to researchers in the design and development of curcumin derivatives/analogues as promising drug candidates in the battle against malaria.

\section{ACKNOWLEDGEMENT}

The authors would like to acknowledge the facilities provided by the Dept. of Pharm. Sc., Dibrugarh University for carrying out the synthesis of the compounds and the Malariology section of Regional Medical Research Centre for permitting the in silico and in vitro studies. The Authors would like to thank SAIF, Panjab University for ${ }^{1} \mathrm{H}$ NMR, ${ }^{13} \mathrm{C}$ NMR and Mass Spectral data.

\section{CONFLICT OF INTEREST}

The authors report no conflict of interest.

\section{REFERENCES}

Aggarwal BB, Harikumar KB. Potential therapeutic effects of curcumin, the anti-inflammatory agent, against neurodegenerative, cardiovascular, pulmonary, metabolic, autoimmune and neoplastic diseases. Int J Biochem Cell Biol. 2009;41(1):40-59.

Ahsan H, Parveen N, Khan NU, Hadi SM. Pro-oxidant, antioxidant and cleavage activities on DNA of curcumin and its derivatives demethoxycurcumin and bisdemethoxycurcumin. Chem Biol Interact. 1999;121(2):161-75.

Ali I, Haque A, Saleem K, Hsieh MF. Curcumin-I Knoevenagel's condensates and their Schiff's bases as anticancer agents: synthesis, pharmacological and simulation studies. Bioorg Med Chem. 2013;21(13):3808-20. 
Almeida LP, Cherubino APF, Alves RJ, Dufose L, Gloria MBA. Separation and determination of the physico-chemical characteristics of curcumin, demethoxycurcumin and bisdemethoxycurcumin. Food Res Int. 2005;38(8):1039-44.

Ames BN, Gurney EG, Miller JA, Bartsch H. Carcinogens as frameshift mutagens: metabolites and derivatives of 2-Acetylaminofluorene and other aromatic amine carcinogens. Proc Natl Acad Sci USA. 1972;69(11):3128-32.

Baell JB, Holloway GA. New substructure filters for removal of pan assay interference compounds (PAINS) from screening libraries and for their exclusion in bioassays. J Med Chem. 2010;53(7):2719-40.

Cheng AL, Hsu CH, Lin JK, Hsu MM, Ho YF, Shen TS, Ko JY, Lin JT, Lin BR, Ming-Shiang W, Yu HS, Jee SH, Chen GS, Chen TM, Chen CA, Lai MK, Pu YS, Pan MH, Wang YJ, Tsai CC, Hsieh CY. Phase I clinical trial of curcumin, a chemopreventive agent, in patients with high-risk or pre-malignant lesions. Anticancer Res. 2001;21(4B):2895-900.

Delano WL. The PyMol molecular graphics system. 2002. Available from: http://www.pymol.org.

Desjardins RE, Canfield CJ, Haynes JD, Chulay JD. Quantitative assessment of antimalarial activity in vitro by a semiautomated microdilution technique. Antimicrob Agents Chemother. 1979;16(6):710-8.

Dubey SK, Sharma AK, Narain U, Misra K, Pati U. Design, synthesis and characterization of some bioactive conjugates of curcumin with glycine, glutamic acid, valine and demethylenated piperic acid and study of their antimicrobial and antiproliferative properties. Eur J Med Chem. 2008;43(9):1837-46.

Eckstein LU, Webb RJ, Van Goethem ID, East JM, Lee AG, Kimura M, O'neill PM, Bray PG, Ward SA, Krishna S. Artemisinins target the SERCA of Plasmodium falciparum. Nature. 2003;424(6951):957-61.

Egan WJ, Merz KM Jr., Baldwin JJ. Prediction of drug absorption using multivariate statistics. J Med Chem. 2000;43(21):3867-77.

Garah, FB, Stigliani, JL, Cosledan F, Meunier B, Robert A. Docking studies of structurally diverse antimalarial drugs targeting PfATP6: no correlation between in silico binding affinity and in vitro antimalarial activity. Chem Med Chem. 2009;4(9):1469-79.
Gelb MH. Drug discovery for malaria: a very challenging and timely endeavor. Curr Opin Chem Biol. 2007;11(4):440-5.

Hatcher H, Planalp R, Cho J, Torti FM, Torti SV. Curcumin: from ancient medicine to current clinical trials. Cell Mol Life Sci. 2008;65(11):1631-52.

Hong-Fang J, Liang S. Interactions of curcumin with the PfATP6 model and the implications for its antimalarial mechanism. Bioorg Med Chem Lett. 2009;19(9):2453-5.

Jung M, Kim H, Nam KY, No KT. Three-dimensional structure of Plasmodium falciparum Ca2+-ATPase(PfATP6) and docking of artemisinin derivatives to PfATP6. Bioorg Med Chem Lett. 2005;15(12):2994-7.

Knoevenagel E. Condensation von Malonsäure mit aromatichen Aldehyden durch Ammoniak und Amine. Berich Deutsch Chem Gesellschaft. 1898;31(3):2596-619. Doi:10.1002/ cber. 18980310308 .

Krishna S, Uhlemann AC, Cameron A, Eckstein U, Ho WY, Croft S, Fischbarg J, Iserovich P, Zuniga F, East M, Lee A, Brady L, Haynes R. Homology model of PfATP6; 2009. Available from: www.rcsb.org.

Kunnumakkara AB, Anand P, Aggarwal BB. Curcumin inhibits proliferation, invasion, angiogenesis and metastasis of different cancers through interaction with multiple cell signaling proteins. Cancer Lett. 2008;269(2):199-225.

Laskowski RA, Swindells MB. LigPlot+: multiple ligandprotein interaction diagrams for drug discovery. J Chem Inf Model. 2011;51(10):2778-86.

Lerner MG, Carlson HA. Apbs plugin for pymol. Ann Arbor: University of Michigan;2008.

Liang G, Li X, Chen L, Yang S, Wu X, Studer E, Gurley E, Hylemon PB, Ye F, Li Y, Zhou H. Synthesis and antiinflammatory activities of mono-carbonyl analogues of curcumin. Bioorg Med Chem Lett. 2008;18(4):1525-9.

Liang G, Shao L, Wang Y, Zhao C, Chu Y, Xiao J Zhao Y, Li $X$, Yang S. Exploration and synthesis of curcumin analogues with improved structural stability both in vitro and in vivo as cytotoxic agents. Bioorg Med Chem. 2009;17(6):2623-31.

Ma XL, Chen C, Yang J. Predictive model of blood-brain barrier penetration of organic compounds. Acta Pharmacol Sin. 2005;26(4):500-12. 
Manohar S, Khan SI, Kandi SK, Raj K, Sun G, Yang X, Calderon Molina AD, Ni N, Wang B, Rawat DS. Synthesis, antimalarial activity and cytotoxic potential of new monocarbonyl analogues of curcumin. Bioorg Med Chem Lett. 2013;23(1):112-6.

Mcgovern, SL, Caselli E, Grigorieff N, Shoichet BK. A common mechanism underlying promiscuous inhibitors from virtual and high-throughput screening J Med Chem. 2002;45(8):1712-22.

Mishra K, Dash AP, Swain BK, Dey N. Antimalarial activities of Andrographis paniculata and Hedyotis corymbosa extracts and their combination with curcumin. Malar J. 2009;8:26.

Mishra S, Karmodiya K, Suroliab N, Surolia A. Synthesis and exploration of novel curcumin analogues as antimalarial agents. Bioorg Med Chem. 2008;16(6):2894-902.

Morris GM, Huey R, Lindstrom W, Sanner MF, Belew RK, Goodsell DS, Olson AJ. AutoDock4 and AutoDockTools4: automated docking with selective receptor flexibility. J Comput Chem. 2009;30(16):2785-91.

Nandakumar DN, Nagaraj VA, Vathsala PG, Rangarajan P, Padmanaban G. Curcumin-artemisinin combination therapy for malaria. Antimicrob Agents Chemother. 2006;50(5):1859-60.

National Vector Borne Disease Control Programme. NVBDCP. Annual Report 2014-15. Government of India. Available from: www.nvbdcp.gov.in/doc/annual-report-nvbdcp-2014-15.pdf.

Odugbemi TO, Akinsulire OR, Aibinu IE, Fabeku PO. Medicinal plants useful for malarial therapy in Okeigbo, Ondo State, Southwest Nigeria. Afr J Trad Cam. 2007;4(2):191-8.

Olliaro, P. Mode of action and mechanisms of resistance for antimalarial drugs. Pharmacol Therapeut. 2001;89(2):207-19.

Padhye S, Yang H, Jamadar A, Cui QC, Chavan D.; Dominiak, K., Mckinney J, Banerjee S, Dou QP, Sarkar FH. New difluoro Knoevenagel condensates of curcumin, their Schiff bases and copper complexes as proteasome inhibitors and apoptosis inducers in cancer cells. Pharm Res. 2009;26(8):1874-80.

Ratti E, Trist D. Continuing evolution of the drug discovery process in the pharmaceutical industry. Pure Appl Chem. 2001;73(1):67-75.

Reddy RC, Vatsala PG, Keshamouni VG, Padmanaban G, Rangarajan PN. Curcumin for malaria therapy. Biochem Biophys Res Commun. 2005;326(2):472-4.
Rieckmann KH, Sax LJ, Campbell GH, Mrema JE. Drug sensitivity of Plasmodium falciparum: an in-vitro microtechnique. Lancet. 1978;1(8054):22-3.

Rishton GM. Active compounds and in vitro false positives in HTS. Drug Discov Today. 1997;2(9):382-4.

Rishton GM. Nonleadlikeness and leadlikeness in biochemical screening. Drug Discov Today. 2003;8(2):86-96.

Roche O, Schneider P, Zuegge J, Guba W, Kansy M, Alanine A, Bleicher K, Danel F, Gutknecht EM, Rogers-Evans M, Neidhart W, Stalder H, Dillon M, Sjögren E, Fotouhi N, Gillespie P, Goodnow R, Harris W, Jones P, Taniguchi M, Tsujii S, Von Der Saal W, Zimmermann G, Schneider G. Development of a virtual screening method for identification of "frequent hitters" in compound libraries. J Med Chem. 2002;45(1):137-42.

Sahu PK, Gupta SK, Thavaselvamd, D, Agarwal DD. Synthesis and evaluation of antimicrobial activity of 4H-pyrimido[2,1-b] benzothiazole, pyrazole and benzylidene derivatives of curcumin. Eur J Med Chem. 2012;54:366-78.

Salas-Burgos A, Iserovich P, Zuniga F, Vera JC, Fischbarg J. Predicting the three-dimensional structure of the human facilitative glucose transporter glut1 by a novel evolutionary homology strategy: insights on the molecular mechanism of substrate migration, and binding sites for glucose and inhibitory molecules. Biophys J. 2004;87(5):2990-9.

Selvam C, Jachak SM, Thilagavathi R, Chakraborti AK. Design, synthesis, biological evaluation and molecular docking of curcumin analogues as antioxidant, cyclooxygenase inhibitory and anti-inflammatory agents. Bioorg Med Chem Lett. 2005;15(7):1793-7.

Shandilya A, Chacko S, Jayaram B, Ghosh I. A plausible mechanism for the antimalarial activity of artemisinin: a computational approach. Sci Rep. 2013;3:2513.

Shankar D, Venugopal S. Understanding of malaria in Ayurveda and Strategies for local production of herbal antimalarials. First International Meeting of the Research Initiative on Traditional Antimalarials Moshi. Tanzania;1999.

Trager W, Jensen JB. Human malaria parasites in continuous culture. Science. 1976;193(4254):673-5. 
Tun KM, Imwong M, Lwin KM, Win AA, Hlaing TM, Hlaing T, Lin K, Kyaw MP, Plewes K, Faiz MA, Dhorda M, Cheah PY, Pukrittayakamee S, Ashley EA, Anderson TJ, Nair S, McDewWhite M, Flegg JA, Grist EP, Guerin P, Maude RJ, Smithuis F, Dondorp AM, Day NP, Nosten F, White NJ, Woodrow CJ. Spread of artemisinin-resistant Plasmodium falciparum in Myanmar: a cross-sectional survey of the K13 molecular marker. Lancet Infect Dis. 2015;15(4):415-21.

Uhe G. Medicinal plants of samoa. Econ Bot. 1974;28(1):1-30.

Veber DF, Johnson SR, Cheng HY, Smith BR, Ward KW, Kopple $\mathrm{KD}$. Molecular properties that influence the oral bioavailability of drug candidates. J Med Chem. 2002;45(12):2615-23.

World Health Organisation. Division of Control of Tropical Diseases. In vitro Micro-test (Mark-III) for the assessment of the response of Plasmodium falciparum to chloroquine, mefloquine, quinine, amodiaquine, sulfadoxine/pyrimethamine and artemisinin. Geneva: WHO; 2001. CTD/MAL/97.20 Rev. 2. 2001 .
World Health Organisation. Status report on artemisinin resistance. WHO 2014. WHO/HTM/GMP/2014.9. Geneva: WHO; 2014. Available from: www.who.int/malaria/ publications/atoz/status-rep-artemisinin-resistance-sep2014.pdf

World Health Organization. World Malaria Report 2014. July 7 , 2015

Yee S. In vitro permeability across Caco-2 cells (colonic) can predict in vivo (small intestinal) absorption in man--fact or myth . Pharm Res. 1997;14(6):763-6.

Zambre AP, Jamadar A, Padhye S, Kulkarni VM. Copper conjugates of knoevenagel condensates of curcumin and their schiff base derivatives: synthesis, spectroscopy, magnetism, ESR, and electrochemistry. Syn React Inorg Met-Org Nano-Met. 2007;37(1):19-27.

Received for publication on $06^{\text {th }}$ October 2016 Accepted for publication on $06^{\text {th }}$ April 2017 